\title{
Pharmacy students and faculty perceptions of online team-based learning due to the COVID-19 pandemic
}

\author{
Frank Yu (D), Jessica Wooster (D), Tianrui Yang (D) \\ Ben and Maytee Fisch College of Pharmacy, The University of Texas at Tyler, United States
}

\author{
Keywords \\ Online learning \\ Pharmacy education \\ Team-based learning \\ Virtual learning
}

\section{Correspondence}

Frank Yu

Ben and Maytee Fisch College of Pharmacy

The University of Texas

3900 University Blvd WTB 348

Tyler

Texas

75799

United States

fyu@uttyler.edu

\begin{abstract}
Aim: This survey study aimed to describe student and faculty experiences and perceptions regarding the sudden shift to delivery of online team-based learning (TBL) due to the COVID-19 pandemic. Method: Data such as perception of engagement and effectiveness of online TBL, challenges and recommendations for improving the online TBL experience were collected. Results: Eighteen (58.1\%) faculty and 154 (75.9\%) students completed the survey. Most students did not feel more engaged with their teammates or instructors using the online format and only one faculty member responded he/she felt more engaged with students via the online TBL format. Fortyone $(26.7 \%)$ students responded they felt the online TBL improves knowledge retention, while no faculty responded they felt online TBL improved students' knowledge retention. The top challenges described include lack of student engagement and technological difficulties. Conclusion: This study showed that a lack of training and preparation for the sudden online TBL transition led to decreased student motivation and engagement.
\end{abstract}

\section{Introduction}

Team-based learning (TBL) is a strategy to enhance students' skills in a collaborative setting while building knowledge and preparing individuals for the real world setting (Addo-Atuah, 2011). Online learning, including $\mathrm{TBL}$, has been described in the literature for various healthcare program settings; however, these studies were mostly in medical education. Studies that included online TBL were descriptive of implementation processes and programs to use, while one study assessed student and educator perspectives participating in online TBL in nursing and optometry students (River et al., 2016; Cross, Robinson \& Todd, 2020; Currey et al., 2020; Dost et al., 2020; Jumat et al., 2020; Vollbrecht, Porter-Stransky \& Lackey-Cornelison, 2020). There remains a need to evaluate the delivery of online TBL in the pharmacy curriculum. The novel coronavirus disease 2019 (COVID-19) pandemic led to the need for an abrupt shift from in-person to online learning for many healthcare programs with minimal time left for preparation and planning to do so. Active learning methods, including TBL, are commonly employed in healthcare programs and could be challenging to deliver via an online learning platform.

At the Fisch College of Pharmacy, the COVID-19 pandemic required an immediate transition from inperson or face-to-face TBL to online or virtual TBL and hybrid learning. Online only TBL courses were delivered online both as synchronous and asynchronous class activities, while hybrid courses included the online TBL model and in-person activities. Hybrid course in-person classes resulted in students sitting at single desks six feet apart and larger classes dispersed across two classrooms, which differed greatly from previous 
semesters where students sat with five to six team members at one large desk. Synchronous classes were delivered in real-time, while asynchronous classes may include pre-recorded lectures, pre-class readings, videos or assignments (Vollbrecht, Porter-Stransky \& LackeyCornelison, 2020). This survey study aimed to describe student and faculty experiences and perceptions regarding the delivery of online TBL.

\section{Methods}

The investigators developed cross-sectional surveys via Qualtrics to capture student and faculty experiences with online TBL. The student survey included 17 questions, and the faculty survey included 14 questions comprised of multiple-choice, select all that apply, Likert scale and free-response questions. Baseline data collected included previous experience with online learning, perception of engagement and effectiveness of online TBL, challenges and recommendations for improving the online TBL experience. Perception questions were formatted via a 5-point Likert scale with $1=$ strongly agree and 5=strongly disagree. The first, second and third-year (P1, P2 \& P3) pharmacy students from the University of Texas at Tyler Ben and Maytee Fisch College of Pharmacy were recruited to participate in this study. Fourth-year students were excluded as they were not exposed to online TBL classes. Faculty recruited were full- or part-time faculty with teaching responsibilities within the Pharm.D. curriculum. Surveys were disseminated via email to faculty and via Canvas online learning management system to students from $3^{\text {rd }}$ to $14^{\text {th }}$ November 2020. Informed consent obtained, and responses were anonymous. While participants were asked to answer each question, they were able to skip questions. Descriptive statistics were used to analyse responses.

\section{Results}

A total of 31 pharmacy faculty members and 203 students were invited to participate in this study. There were 18 (58.1\%) faculty and 154 (75.9\%) students participating in the survey. Baseline information included in Table I.

Of 122 students that reported previous online class experiences prior to pharmacy school, 27 (17.5\%) indicated that they preferred only the online format, while 88 (57.2\%) responded that they prefer either online or a hybrid curriculum. Most students (83.1\%) indicated they prefer TBL regardless of course format.
Three (16.7\%) faculty responded, indicating that they preferred either online or hybrid format.

Table I: Baseline characteristics of student respondents

\begin{tabular}{|c|c|}
\hline Student survey & $\begin{array}{c}\text { Responses } \\
\text { n (\%) }\end{array}$ \\
\hline \multicolumn{2}{|l|}{ Classification } \\
\hline P1 & $50(32.5)$ \\
\hline $\mathrm{P} 2$ & $62(40.3)$ \\
\hline P3 & $42(27.3)$ \\
\hline \multicolumn{2}{|l|}{ Highest level of education } \\
\hline Pre-requisite only & $41(26.6)$ \\
\hline Associate degree & $45(29.2)$ \\
\hline Bachelor's degree & $60(39.0)$ \\
\hline Master's degree & $4(2.6)$ \\
\hline Doctorate degree & $4(2.6)$ \\
\hline \multicolumn{2}{|l|}{ Age group } \\
\hline$<20$ & $1(0.7)$ \\
\hline $20-24$ & $72(46.8)$ \\
\hline $25-29$ & $55(35.7)$ \\
\hline $30-34$ & $13(8.4)$ \\
\hline $35-39$ & $6(3.9)$ \\
\hline$>39$ & $7(4.6)$ \\
\hline Previous experience with online classes & $122(79.2)$ \\
\hline \multicolumn{2}{|l|}{ Learning modality this semester } \\
\hline Remote only & $21(13.6)$ \\
\hline Hybrid with remote and face-to-face classes & $133(86.4)$ \\
\hline \multicolumn{2}{|l|}{ Faculty survey } \\
\hline \multicolumn{2}{|l|}{ Years of teaching experiences } \\
\hline$<1$ year & $1(5.6)$ \\
\hline $1-5$ years & $9(50.0)$ \\
\hline $6-10$ years & $1(5.6)$ \\
\hline$>10$ years & $7(38.9)$ \\
\hline \multicolumn{2}{|l|}{ Years of TBL teaching experiences } \\
\hline$<1$ year & $1(5.6)$ \\
\hline $1-5$ years & $14(77.8)$ \\
\hline $6-10$ years & $3(16.7)$ \\
\hline Prior online teaching experiences & $3(16.7)$ \\
\hline \multicolumn{2}{|l|}{ Course format (autumn 2020) } \\
\hline Hybrid with online and face-to-face & $13(72.2)$ \\
\hline Online only & $7(38.9)$ \\
\hline Face-to-face only & $2(11.1)$ \\
\hline Pre-recorded lectures & $3(16.7)$ \\
\hline \multicolumn{2}{|l|}{ Teaching load (autumn 2020) } \\
\hline $1-5$ days & $3(16.7)$ \\
\hline $6-10$ days & $3(16.7)$ \\
\hline $11-15$ days & $7(38.9)$ \\
\hline $16-20$ days & $2(11.1)$ \\
\hline$>20$ days & $3(16.7)$ \\
\hline \multicolumn{2}{|l|}{ Changes made to courses taught } \\
\hline Increased use of Zoom breakout rooms & $12(66.7)$ \\
\hline Increased use of pre-recorded lectures & $4(22.2)$ \\
\hline $\begin{array}{l}\text { Audience response systems } \\
\text { (e.g. Poll Everywhere, Kahoot, etc.) }\end{array}$ & $4(22.2)$ \\
\hline Convert class from TBL to lecture-style & $5(27.8)$ \\
\hline
\end{tabular}

There were 51 (33.1\%) students who agreed or strongly agreed that online TBL classes make them more motivated to attend class compared to in-person classes, while $42(27.2 \%)$ students agreed or strongly agreed they 
feel more motivated to participate in online classes (Table II). There were 30 (19.5\%) students that agreed or strongly agreed they feel more engaged with their teammates, while 38 (24.7\%) students agreed or strongly agreed they feel more engaged with their instructor in an online TBL format compared to in-person. In a similar question in the faculty survey, one participant (5.6\%) agreed that he/she felt more engaged with students using the online TBL format.

Table II: Students' and faculty members' perceptions of online TBL classes compared with the face-to-face format

\begin{tabular}{|c|c|}
\hline Student survey & $\begin{array}{l}\text { Responses, } \\
\text { median } \\
\text { (mean)* }\end{array}$ \\
\hline $\begin{array}{l}\text { I feel more motivated to attend TBL classes } \\
\text { delivered online compared to face-to-face. }\end{array}$ & $3(3.15)$ \\
\hline $\begin{array}{l}\text { I feel more motivated to participate in TBL } \\
\text { classes delivered online compared to face-to- } \\
\text { face. }\end{array}$ & $3(3.25)$ \\
\hline $\begin{array}{l}\text { I feel more engaged with the course instructor } \\
\text { in TBL classes delivered online compared to } \\
\text { face-to-face. }\end{array}$ & $5(3.51)$ \\
\hline $\begin{array}{l}\text { I feel more engaged with my teammates in TBL } \\
\text { classes delivered online compared to face-to- } \\
\text { face. }\end{array}$ & $5(3.58)$ \\
\hline $\begin{array}{l}\text { I feel that online delivery of TBL will improve my } \\
\text { retention of knowledge compared to face-to- } \\
\text { face. }\end{array}$ & $5(3.36)$ \\
\hline \multicolumn{2}{|l|}{ Faculty survey } \\
\hline $\begin{array}{l}\text { I feel confident that I can deliver my TBL classes } \\
\text { in an online format. }\end{array}$ & $2(2.72)$ \\
\hline $\begin{array}{l}\text { I feel more engaged with students in TBL classes } \\
\text { delivered online compared to face-to-face. }\end{array}$ & $4.5(4.28)$ \\
\hline $\begin{array}{l}\text { I feel that online delivery of TBL will improve } \\
\text { students' retention of knowledge compared to } \\
\text { face-to-face. }\end{array}$ & $3(3.94)$ \\
\hline
\end{tabular}

When subgroup analysis was conducted on student results by class year, $50 \%$ of P3 students and $45.16 \%$ of P2 students prefer face-to-face format compared with only $30 \%$ of P1 students. When asked about an agreement with the statement "I feel more motivated to participate in TBL classes delivered online compared to face-to-face", $45.24 \%$ of P3 students and $50 \%$ of P2 students either disagree or strongly disagree, compare with only $38 \%$ of P1 students. Items on challenges encountered in online TBL classes, $40.3 \%$ of $P 2$ students and $42.9 \%$ of P3 students selected this item compared with $24.0 \%$ of P1 students.

Common challenges to online TBL described by students' responses included technology difficulties (72.1\%), changes to TBL delivery (57.8\%), and lack of teammate engagement (57.8\%). Similar challenges were reported by the faculty (Table III). Other challenges with online TBL described by faculty members' responses included reduced efficiency, inability to stimulate robust discussion, and lack of familiarity with the online format. Students were asked what would help address these challenges. Responses included posting lecture videos and answer keys online $(72.7 \%)$, increased use of Zoom breakout rooms $(61.0 \%)$ and audience response programs such as Kahoot (55.2\%).

Table III: Challenges encountered transitioning to online TBL courses

\begin{tabular}{|c|c|c|}
\hline Challenges & $\begin{array}{c}\text { Student } \\
\text { response } \\
\mathrm{n}(\%)\end{array}$ & $\begin{array}{c}\text { Faculty } \\
\text { response } \\
\mathrm{n}(\%)\end{array}$ \\
\hline Technology difficulties & $111(72.1)$ & $13(72.2)$ \\
\hline Changes to the TBL delivery & $89(57.8)$ & $9(50.0)$ \\
\hline $\begin{array}{l}\text { Lack of teammate/student } \\
\text { engagement }\end{array}$ & $89(57.8)$ & $14(77.8)$ \\
\hline $\begin{array}{l}\text { Lack of accessibility of } \\
\text { course instructors }\end{array}$ & $55(35.7)$ & Not applicable \\
\hline $\begin{array}{l}\text { Online exams using online } \\
\text { proctoring systems }\end{array}$ & $60(39.0)$ & $5(27.8)$ \\
\hline $\begin{array}{l}\text { Difficulty focusing during } \\
\text { class }\end{array}$ & $87(56.5)$ & $3(16.7)$ \\
\hline $\begin{array}{l}\text { Reduced student } \\
\text { attendance }\end{array}$ & Not applicable & $7(38.9)$ \\
\hline
\end{tabular}

Students responded that re-working class applications (74.7\%), re-reading pre-class materials $(65.6 \%)$, and studying alone $(61.0 \%)$ were methods they utilised this semester to increase academic success. Faculty members' responses regarding tools or resources that were helpful in the transition to online TBL classes included technology support (100\%), advice from colleagues (66.7\%) and Zoom workshops (61.1\%). Faculty members' ideas on helpful resources for further support included workshops to debrief about online TBL class experiences and brainstorm ideas for future semesters, development of policies and procedures for online learning and hold students accountable and increased support for online classes using teaching assistants.

\section{Discussion}

While virtual learning environments are not novel, it was a new experience for a college of pharmacy used to faceto-face TBL prior to COVID-19. Cross and colleagues described the transition from face-to-face TBL to synchronous online TBL in medical education as a result of COVID-19. They did not publish survey results but noted students were initially less engaged with online learning; however, when they simulated TBL using Zoom breakout rooms, Microsoft Forms for assessments and 
Excel for reporting results, students conveyed increased engagement, deeper learning, and ease of technology (Cross et al., 2020). Similarly, a study comparing inperson to virtual TBL in nursing and optometry students showed mean student engagement scores significantly increased in the virtual format. This study utilised a digital TBL software program that aligned with the traditional TBL paradigm in a virtual format (Currey et al., 2020). In contrast, Vollbrecht and colleagues found that synchronous online TBL delivered via Microsoft Teams, use of breakout rooms and a polling platform for applications were found to be less than ideal, learning was significantly more difficult, and required the use of more outside resources than used previously in student evaluations (Vollbrecht et al., 2020). Lastly, Dost and colleagues found that students did not find online teaching engaging, felt they had limited opportunities to ask questions, did not feel it was as effective as face-toface teaching and did not prefer online over face-to-face teaching (Dost et al., 2020). The findings of online learning perspectives varied in these studies, which may be explained by multiple factors, such as differences in faculty training, technologies used, and ample support, including administrative, technological, and logistical personnel.

The large proportion of students that prefer online TBL could be due to prior experiences with online learning. However, when looking into class differences, a larger proportion of P3 students preferred face-to-face TBL compared to P1 students suggesting there may be other factors besides prior online class experience. P1 students were native to online TBL as they began their coursework during the COVID-19 pandemic. However, P3 students spent almost two years learning in the face-to-face TBL format. Those differences likely explain the variable preferences for face-to-face learning. Faculty members who reported a lack of online teaching experience may be those who responded they prefer to convert to traditional lecture-style rather than TBL classes. A lack of training, guidance and support for the sudden transition to online TBL likely contributed to faculty reported challenges. This is further supported by faculty responses on ideas for beneficial resources, including additional workshops, shared experiences between colleagues, administrative and technological support. Vollbrecht's study recommends increasing the facultyto-student ratio for online TBL sessions with additional support staff to assist with class logistics such as monitoring chat and breakout rooms, technological support, and facilitation of activities. This may not be feasible based on available staff and faculty during class times (Vollbrecht et al., 2020). The lack of student engagement could be due to a combination of both student and faculty member unfamiliarity with technology programs utilised, as well as a lack of adequate training during the shift from in-person to online TBL.

Prior to COVID-19, college culture included students' ease of access to faculty outside of the classroom for further discussion and guidance on course content. Due to COVID, many students were unable to readily interact with faculty, as supported by the third of students reporting a lack of faculty accessibility. However, fewer P1 respondents reported a lack of instructor accessibility, which is likely due to them being unaware of this resource that their upperclassmen had in previous years. Vollbrecht's study recommends establishing virtual office hours and scheduling virtual appointments with students to improve accessibility (Vollbrecht et al., 2020). However, due to the inconvenience of those added steps, students may still feel that their professors are less accessible. Similarly, students were used to frequently interacting with classmates in and outside the classroom at the college. Rather than lively team discussions during in-person classes, students shifted to communicating online in class via Zoom chat and breakout rooms or collaborating via google docs. The use of these online platforms to communicate and work as a team may have resulted in reduced engagement and focus. This finding is consistent with Dost's study, where students reported a lack of motivation, difficulty concentrating and lack of contact with colleagues as limitations with online learning (Dost et al., 2020).

Study strengths include high response rates minimizing selection bias, the inclusion of both faculty and student perspectives, and timely distribution of surveys minimising recall bias. Study limitations are potentially being underpowered, a lack of items to assess wellbeing as factors related to stress or burnout secondary to COVID-19 may have influenced results, a lack of free-text responses to capture additional themes, a lack of comparison to survey results prior to implementation of online TBL, and results limited to a single institution.

\section{Conclusions}

This study showed a lack of training and preparation for the sudden online TBL transition led to decreased student motivation and engagement. The transition from in-person to online learning is a continuous quality improvement process, and future research should explore effective technology programs and guidance to keep learners engaged and obtain the necessary content for pharmacy and healthcare education. 


\section{References}

Addo-Atuah, J. (2011). Performance and perceptions of pharmacy students using Team-based Learning (TBL) within a global health course. Innovations in pharmacy, 2(2). https://doi.org/10.24926/iip.v2i2.220

Cross, C.E., Robinson, C., \& Todd, E. (2020). Development and implementation of a synchronous online TBL using microsoft forms. Medical science educator, 1-3. https://doi.org/10.1007/s40670020-01133-6

Currey, J., Sprogis, S.K., Burdeu, G., Story, I., Considine, J., O’Donnell, M., Gentle, A., Backhouse, S., \& Oldland, E. (2020). Stakeholder acceptance of digital team-based learning. Nurse education in practice, 46, 102833. https://doi.org/10.1016/j.nepr.2020.102833

Dost, S., Hossain, A., Shehab, M., Abdelwahed, A., \& AlNusair, L. (2020). Perceptions of medical students towards online teaching during the COVID-19 pandemic: a national cross-sectional survey of 2721 UK medical students. BMJ Open, 10(11), e042378. https://doi.org/10.1136/bmjopen2020-042378

Jumat, M.R., Wong, P., Foo, K.X., Lee, I.C. J., Goh, S.P. L., Ganapathy, S., Tan, T.Y., Loh, A.H.L., Yeo, Y.C., Chao, Y., Cheng, L.T., Lai, S.H., Goh, S.H., Compton, S., \& Hwang, N.C. (2020). From trial to implementation, bringing Team-Based Learning Online-DukeNUS medical school's response to the COVID-19 pandemic. Medical science educator, 1-6. https://doi.org/10.1007/s40670020-01039-3

River, J., Currie, J., Crawford, T., Betihavas, V., \& Randall, S. (2016). A systematic review examining the effectiveness of blending technology with team-based learning. Nurse education today, 45, 185-192. https://doi.org/10.1016/j.nedt.2016.08.012

Vollbrecht, P.J., Porter-Stransky, K.A., \& Lackey-Cornelison, W.L. (2020). Lessons learned while creating an effective emergency remote learning environment for students during the COVID-19 pandemic. Advances in physiology education, 44(4), 722-725. https://doi.org/10.1152/advan.00140.2020 